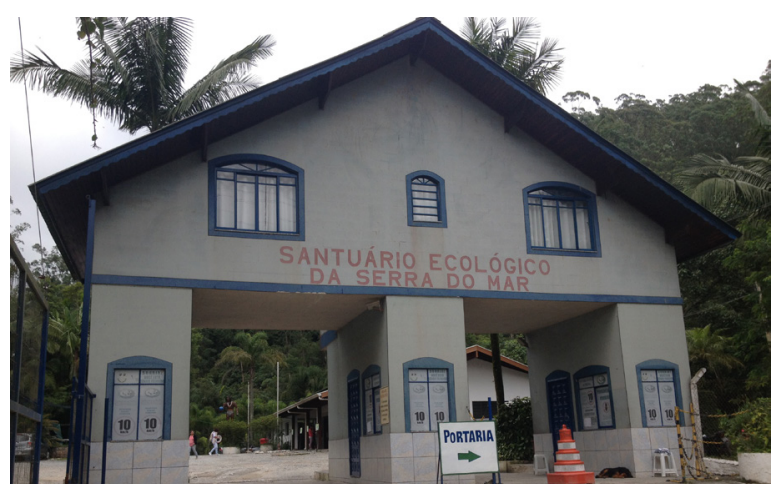

*Mestranda em História pela Pontifícia Universidade Católica de São Paulo (PUC-SP). Graduada em História, com especialização em Gestão Pública e Restauração de Patrimônio Arquitetônico. Funcionária do Conselho de Defesa do Patrimônio Histórico, Arqueológico, Artístico e Turístico (CONDEPHAAT) desde 1991. Desde 2011, ocupa cargo de Diretor Técnico do Grupo de Estudos de Inventário, responsável pela instrução dos pedidos de tombamento e registro protocolados no órgão.

1. Unidade de Preservação do Patrimônio Histórico, criado em 2006 pelo Decreto 50.941/06 e que dá respaldo técnico e administrativo para as decisões do CONDEPHAAT.
**Possui graduação em História pela University Of Wisconsin (1975), mestrado em História Social pela Universidade Estadual de Campinas (Unicamp) (1984) e doutorado em História Social pela Universidade de São Paulo (USP) (1994). É docente do Programa de Pós-Graduação e do Curso de Graduação em História da Pontifícia Universidade Católica de São Paulo (PUC-SP) desde 1986 e atualmente, coordena o Centro de Documentação (CEDIC) da mesma Universidade.

\title{
O reconhecimento do patrimônio cultural de matriz africana - tombamento e registro de territórios tradicionais em São Paulo
}

The recognition of the cultural heritage of African origins - Landmarking and registration of traditional sites in São Paulo.

Elisabete Mitiko Watanabe* e Heloisa de Faria Cruz ${ }^{\star \star}$

\section{Resumo}

Em meio a trajetória recente de reconhecimento de bens ligados à história e memória das populações negras pelo órgão de preservação do patrimônio no Estado de São Paulo, o presente artigo discute questões sobre a adequação da utilização dos instrumentos do tombamento e do registro no trabalho de identificação e proteção de territórios de matriz africana como bem cultural, a partir dos estudos técnicos desenvolvidos sobre os espaços de Candomblé e Umbanda pela UPPH ${ }^{1}$, que balizaram a decisão do CONDEPHAAT. Na reflexão que propõe busca contribuir com a discussão sobre a importância da preservação destes espaços como suportes materiais da cultura afro-brasileira em São Paulo.

Palavras-chave: Patrimônio cultural. CONDEPHAAT. Candomblé. Umbanda.
Abstract

Amid the recent recognition of assets linked to the history and memory of black populations by the heritage preservation agency in the State of São Paulo, Conselho de Defesa do Patrimônio Histórico, Artístico e Turístico do Estado de São Paulo (CONDEPHAAT), the present article discusses issues about the adequacy of usage of landmark instruments and of registration in the identification and protection of Afro-descendent territories as cultural asset, based on technical studies on Candomblé and Umbanda sites conducted by UPPH, that guided decisions made by CONDEPHAAT. This work seeks to contribute to the discussion on the importance of preserving these spaces, as they are material supports for the African-Brazilian culture in São Paulo.

Keywords: Cultural heritage. CONDEPHAAT. Candomblé. Umbanda. 


\section{Introdução}

presente artigo tem por objetivo apresentar reflexões acerca da proteção de territórios tradicionais de matriz africana, a partir da experiência da instrução técnica dos pedidos de tombamento de 6 espaços ligados à prática do Candomblé e Umbanda em São Paulo, desenvolvido ao Iongo de 2017 e 2018.

Os pedidos foram protocolados em tempos diferentes e as solicitações foram assinadas pelos responsáveis (e proprietários) dos terreiros, acompanhado de ampla documentação e laudos antropológicos. A partir de conversas iniciais com estes pesquisadores e com as lideranças dos terreiros, foi criado o Grupo de Trabalho Territórios Tradicionais de Matriz Africana Tombados². Assim, o presente artigo é fruto das discussões realizadas no processo de instrução técnica dos pedidos de tombamento destes lugares.

Como indicam os vários estudos sobre a questão, pautadas desde suas origens pelo predomínio da matriz eurocêntrica, as políticas patrimoniais e de preservação do país só muito recentemente, e de forma ainda bastante tímida, passaram a incorporar referências culturais afro-brasileiras como índice de valorização do patrimônio cultural. Como indica Fonseca (1996, p. 156), assumindo "demandas de setores até então marginalizados pelas políticas culturais", a partir das décadas finais do século $X X$, referências patrimoniais voltadas para as tradições populares e as matrizes indígenas e afro-brasileiras passam também a ser incorporadas ao repertório cultural nacional.

A diversificação de bens indicados para integrar o patrimônio histórico e artístico nacional pode ser interpretada, juntamente com a participação maior da sociedade nos pedidos de tombamento, como um indício de que o patrimônio estava sendo então considerado pela sociedade brasileira, mesmo que de maneira ainda bastante limitada, como campo para afirmação de novas identidades coletivas, que se valiam dos bens 
3. Este é o número de tombamento realizados $\mathrm{e}$, muitas vezes, um tombamento recai sobre centenas de bens, como é o caso dos Centros Históricos e Bairros. Estima-se que o número de bens tombados seja de cerca de 3 mil.

4. Fonte: www.CONDEPHAAT. sp.gov.br e listas de uso interno da Unidade de Preservação do Patrimônio Histórico, que dá suporte administrativo e técnico ao CONDEPHAAT.

5. Atual IPHAN - Instituto do Patrimônio Histórico e Artístico Nacional. culturais como referências materiais e simbólicas (FONSECA, 1996; p. 158).

Em São Paulo, a atuação do CONDEPHAAT sobre o tema também se deu de forma tímida, se concentrando na década de 1980, com a proteção de igrejas de Nossa Senhora do Rosário dos Homens Pretos e de São Benedito, um bairro de origem quilombola e um único terreiro. Apenas muito recentemente, nos anos 2010 , outros bens seriam objeto de estudos pelo órgão, como clubes sociais negros, a retomada da proteção de comunidades quilombolas e terreiros, além das novas possibilidades trazidas com o registro do patrimônio imaterial, a partir da edição do Decreto Estadual 57.439/11.

\section{O lugar do patrimônio de matriz africana nos bens reconhecidos pelo CONDEPHAAT}

O CONDEPHAAT - Conselho de Defesa do Patrimônio Histórico, Artístico, Arqueológico e Turístico é o órgão estatal de São Paulo, responsável pelo reconhecimento do patrimônio cultural paulista. Acumula, em sua trajetória de 50 anos, um total de 499 tombamentos $^{3}$, dois registros de patrimônio imaterial e 125 processos de estudo de tombamento 4 .

Neste universo de bens, constam prédios institucionais (fóruns, casas de câmara e cadeia, escolas), igrejas, fazendas, residências, centros históricos, áreas naturais, acervos, ferrovias, hospitais, comunidade quilombolas, terreiro, clubes, cinemas, etc. que foram reconhecidos por justificativas variadas, mas que mantém alguma vinculação com a história paulista.

Embora ainda não consiga abarcar, de forma plena, todos os grupos sociais da sociedade, os tombamentos realizados pelo CONDEPHAAT se configuram como uma nova forma de construir a história, incorporando as novas tendências historiográficas, que surgem a partir da década de 1960 (FENELON, 1993, p. 73) de:

(...) ampliar o mapa de conhecimento histórico e legitimar novas áreas para investigação. Essa ampliação fez surgir ou possibilitou a incorporação de inúmeras temáticas como o urbano, a mulher, a família, o crime, a infância, a educação e outros, todos reclamando um lugar dentro do contexto mais amplo da História Social e da temática da cultura.

Este entendimento sobre a dimensão social do patrimônio se deu de forma gradual, sendo percebida através da mudança dos critérios de avaliação e nos tipos de bens tombados ao longo da trajetória do CONDEPHAAT.

Criado em 1968, o órgão estadual herdou a forma tradicional de preservação do então SPHAN ${ }^{5}$, que entendia a proteção do patrimônio como forma de construção da identidade nacional, o que levou ao tombamento de bens do século XVIII de estilo neocolonial, que se traduziu, no CONDE- 
6. Processo 00610/75.

7. Processos $00306 / 73$ e $20.814 / 79$ e $22.366 / 82$.

8. Processos 00496/74 e 20.601/79).

9. Processo 20.130/76.

10. Varine Bohan dirigiu 0 Conselho Internacional de Museus (Icom), da Unesco no período de 1965 a 1974.
PHAAT, na proteção de imóveis ligados ao Império e vinculados a ciclos econômicos (RODRIGUES, 1996, p. 179), que tanto se configuravam como documentos da arquitetura, como também se revestiam de tradição nobiliárquica, considerando sua vinculação com grandes heróis do passado.

Neste sentido, os primeiros tombamentos realizados pelo órgão estão afinados com o que Walter Benjamin (2012) nomeia como a história dos vencedores, que traz, a contrapelo, as memórias de sujeitos não nomeados, mas que são parte intrínseca do processo histórico.

Neste contexto, caberia assumir que ao tombar uma fazenda de café, esta proteção traz a contrapelo a memória dos negros escravizados que ali trabalharam e também a barbárie da escravidão. Mas isso nunca aparece. Os pareceres técnicos constantes dos diversos processos de tombamento, trazem a biografia, linhagem e vida política de seu dono, a arquitetura da casa sede, a inserção da fazenda no território do Estado, sua participação no ciclo econômico.

A figura do escravo surge (quando surge) apenas numericamente (quanto maior o número, melhor se caracteriza a pujança da fazenda). A senzala e o pelourinho, se ainda existirem, são elementos acessórios, e servem apenas para destacar a integridade do conjunto, o que amplia a justificativa para sua proteção. E nesta perspectiva, a escravidão aparece de forma naturalizada, sem quaisquer reflexões.

A Constituição Federal de 1988 é o marco legal que traz a ampliação do conceito de patrimônio. Contudo, a lista dos bens tombados pelo CONDEPHAAT antes deste período, demonstra que sua atuação já direcionava sua ação para novos tipos de bens, embora ainda vinculada à ideia da monumentalidade. Na década de 1970, foram tombados vários bens que exemplificam este novo olhar: escola (Instituto de Educação Caetano de Campos - São Paulo6), áreas naturais (Juréia e Serra do Japi ${ }^{7}$ ), edificações ligadas à imigração (Cemitério Japonês - Alvares Machado; Hospedaria dos Imigrantes - São Paulo); e mesmo bens cujo valor se referia às práticas culturais (Aldeia Caiçara de Picinguaba - Ubatuba ${ }^{9}$ ), todos protegidos antes da Constituição. Mas ao mesmo tempo mantinha a linha conservadora de proteção de bens monumentais.

De acordo com RODRIGUES (2000, p. 73) tal mudança de perspectiva deve-se, em parte, a realização de um curso em 1974, organizado pelo CONDEPHAAT, IPHAN e Departamento de História da Arquitetura da FAU/USP, que contou com a participação de especialistas estrangeiros, incluindo Varine Bohan ${ }^{10}$, que trouxe novas interpretações sobre o conceito de patrimônio, considerado como um "fato cultural composto por três categorias de elementos, o meio ambiente, o conhecimento e tudo o que o homem fabricou, isto 
11. No Processo 24.929/86 foram tombadas em conjunto 123 escolas destas 137

12. Processo $23.370 / 85$.

13. Processo $24.601 / 86$

14. Processos $33.189 / 95$ $28.728 / 91,72.097 / 14$ $72.140 / 14$ e $72.143 / 14$ respectivamente.

15. O tombamento mais emblemático de área natural refere-se à Serra do Mar, objeto do Processo 20.868/79.

16. Processo $21.955 / 82$. é, os bens culturais". Também parece importante indicar que em 1982, houve o concurso para contratação de 33 arquitetos e 11 historiadores, formando o corpo técnico efetivo do CONDEPHAAT, permitindo-lhe a ampliação de sua atuação.

RODRIGUES (2000; p. 128) destaca que:

Tomando contato com o pensamento de Walter Benjamin e participando de diversas discussões, entre as quais algumas de caráter técnico, os técnicos passaram a perceber mais claramente as relações entre preservação e memória; (...).

E neste contexto, a história do cotidiano, do trabalho, da educação, da saúde também começar a surgir dentre os bens tombados.

Assim, nesta fase, temos tombamentos de um conjunto de 137 escolas construídas na Primeira República ${ }^{11}$, que buscou preservar a memória da política pública implementada no período de 1890 a 1930 em São Paulo, além da memória afetiva ligadas a estes lugares; hospitais como o Sanatório Vicentina Aranha ${ }^{12}$ (São José dos Campos), Hospital do Juquery ${ }^{13}$ (Franco da Rocha), Asilos Colônia de tratamento de hanseníase (Guarulhos, Bauru, Itu, Casa Branca e Mogi das Cruzes ${ }^{14}$ ) como forma de reconhecer a memória do papel do Estado no tratamento de saúde, mas também dos pacientes, que foram estigmatizados por causa de sua doença (tuberculose, loucura e lepra); Serras, Ilhas, Morros, que visaram a preservação do patrimônio ambiental do Estado ${ }^{15}$.
Além destes, destacamos o tombamento da Casa de Dona Yayá (Bela Vista - São Paulo ${ }^{16}$ ), que registra a história de Sebastiana de Melo Freire, em que se contextualiza o papel da mulher na sociedade paulista e o tratamento da loucura no início do século $X X$.

Mas mesmo com esta ampliação, a cultura de matriz africana tem sido tratada de forma marginal, com poucos bens tombados. Até o ano de 1990, O CONDEPHAAT tombou os seguintes bens ligados, direta ou indiretamente, a cultura de matriz africana:

- Capela Nossa Senhora do Rosário dos Homens Preto de Ivaporunduva Eldorado (Processo 18.942/74);

- Igreja São Benedito - São José dos Campos (Processo 20.993/79);

- Igreja Nossa Senhora do Rosário dos Homens Pretos de Penha de França São Paulo (Processo 20.776/79);

- Cemitério dos Escravos - São José do Barreiro (Processo 00496/74)

- Terreiro Axé llê Obá - São Paulo (Processo 26.110/88)

- Bairro do Cafundó - Salto de Pirapora (Processo 26.336/88)

Como se vê, os tombamentos produzidos pelo órgão relativos à cultura de matriz africana são representados, em sua maioria, pela sua face religiosa. É verdade que, como aponta SILVA 
17. Sobre a participação das religiões de matriz africana na formação da cultura brasileira, veja Amaral e Silva, 1996; 2006; Prandi, 2007; Silva, 2013. Informações também disponibilizadas no site $h$ ttp:// www.doafroaobrasileiro.org/ DoafroaoBrasileiro.html
(2005), a religião se tornou uma forma de resistência à dominação católica imposta pelos brancos, quando os negros buscaram conciliar suas práticas aos elementos da doutrina católica, dando origem a diversas religiões, como tambor de mina e pajelança (Maranhão), candomblé (Bahia), xangô (Pernambuco), o batuque (Rio Grande do Sul), sendo que algumas se perderam com o tempo enquanto outras permaneceram até os dias atuais, adaptando-se à dinâmica da sociedade.

De acordo com SILVA (2005, p. 50),

o terreiro associou-se assim ao protesto do negro contra as condições da escravidão, colocando tanto sua organização a favor da luta pela libertação, como no plano religioso, promovendo a crença na magia compartilhada por pessoas que tinham em comum, além da condição de subordinação, a esperança na transformação dessas condições.

Após o fim da escravidão, os terreiros ganham outro destaque, pois se transformam em locais de sociabilidade de negros, onde se buscou o conforto religioso e a esperança diante de uma vida cheia de dificuldades. Para além disso, é inegável a contribuição das religiões de matriz africana para a formação da cultura brasileira, em termos de festividades coletivas (carnaval, maracatu, afoxé, festas de largo, congadas), em diversos campos artísticos e estéticos (samba, capoeira, literatura, cinema), nos gostos alimentares (feijoada, acarajé), enfim na formação de um ethos reconhecível como um legado nacional e africano em nossa identidade multiétnica e multicultural ${ }^{17}$.

Para aqueles que encontraram sua religiosidade no catolicismo, a lgreja também criou meios para que os negros pudessem professar sua fé, incentivando a criação de irmandades e confrarias específicas para eles, sendo a de Nossa Senhora do Rosário a mais conhecida, de modo que o negro também influenciou a religião católica no Brasil. Para além de ser apenas uma religião, a Irmandade Nossa Senhora do Rosário se configurou como uma ampla rede de assistência aos negros, tendo participado ativamente do processo de abolição da escravidão.

Deste modo, os bens relacionados à cultura de matriz africana, se configuraram, em sua origem, como lugares de resistência, e sua permanência, enquanto bens protegidos oficialmente, permitem a preservação desta história, se constituindo como instrumento de reconhecimento desta cultura.

Contudo, é preciso registrar que, na leitura dos respectivos processos de tombamento, embora a história do bem se vincule à memória africana, nem todos os bens foram tombados por este motivo. Alguns foram tombados por conta de sua arquitetura, não havendo informações a respeito de sua ligação com os negros, como é o caso das igrejas de Nossa Senhora do Rosário 
dos Homens Pretos, tanto a de Eldorado como a de São Paulo, no Bairro da Penha ${ }^{18}$. Saliente-se que daquela relação os únicos bens que, de fato, foram tombados por sua ligação a história afro-brasileira foram o Terreiro Axé llê Obá e o Bairro do Cafundó ${ }^{19}$.

Aqui BENJAMIN (2012; p. 243) traz novamente questões quando destaca que "o passado só se deixa capturar como imagem que relampeja irreversivelmente momento de sua conhecibilidade". Se ao reconhecer um bem, a pesquisa não identificar e registrar os sujeitos envolvidos na sua historicidade, a preservação do patrimônio cumpre seu papel de forma parcial, já que, embora mantida a materialidade do bem, sua histó-

\begin{tabular}{|l|l|}
\hline $\begin{array}{l}\text { Casa de culto afro-descendente Dambala Kuere Rho } \\
\text { Bessein - Rua dos Amoritas } n^{\circ} 629\end{array}$ & SANTO ANDRÉ \\
\hline Terreiro de Candomblé Santa Bárbara - Rua Ruiva n 90 & SÃO PAULO \\
\hline $\begin{array}{l}\text { Sede do llê Afro Brasileiro Ode Lorecy - Rua Madureira n } \\
165 \text { e Rua Monte Alegre n } 126\end{array}$ & EMBU DAS ARTES \\
\hline $\begin{array}{l}\text { Templo de culto sagrado Tatá Percio do Battistini llê } \\
\text { Alaketu Ase Ayra - Rua Antônio Batistini n²26 }\end{array}$ & SÃO BERNARDO DO CAMPO \\
\hline $\begin{array}{l}\text { Centro Cultural llê Olá Omi Ase Opo Araka - Al. dos } \\
\text { Pinheirais n }{ }^{\circ} 270\end{array}$ & SÃO BERNARDO DO CAMPO \\
\hline $\begin{array}{l}\text { Santuário Nacional da Umbanda - Estrada do Montanhão } \\
\text { s/ } n^{\circ}\end{array}$ & SANTO ANDRÉ \\
\hline
\end{tabular}

Fonte: Quadro elaborado pela autora ria, de fato, não é conhecida. De todo modo, sua permanência, possibilitada pela proteção oficial, permite que, no futuro, se façam novas interpreprojetos de restauro, o que não seria possível se o bem não estivesse preservado.

Instrumentos de proteção do patrimônio cultural: o tombamento e o registro aplicado a terreiros de Candomblé e Umbanda

Após um longo período sem receber solicitações de proteção de terreiros, entre 2013 e 2017 foram protocolados um total de 6 pedidos de tombamento, sendo 5 de Candomblé e um de Umbanda: tações sobre seu valor, inclusive em eventuais
18. Processos 18.942/70 e 20.776/79.

19. Processos 26.110/88 e $26.336 / 88$. 
20. O antropólogo Vagner Gonçalves da Silva participou do primeiro pedido de tombamento de terreiro em São Paulo, o Axé llê Obá (1987), e elaborou juntamente com uma equipe de pesquisadores os laudos antropológicos dos terreiros de Santa Barbara (2005 e 2016), lle Olá Omi Ase Opo Araka (2016), llê Afro-brasileiro Ode Lorecy (2014) e Santuário Nacional da Umbanda (2017). Realizou também os estudos complementares de atualização ao laudo da Casa Dambala Kuere Rho Bessein (2016).

21. As lideranças à época eram: Pai Dancy (Casa de culto afro-descendente Dambala Kuere Rho Bessein), Mãe Pulquéria (Terreiro de Candomblé Santa Bárbara), Pai Leo (llê Afro Brasileiro Ode Lorecy), Mãe Luzinha, Mãe Gui, Mãe Daniela, Pai Giba e Pai Carlinhos (Templo de culto sagrado Tatá Percio do Battistini llê Alaketu), Mãe Carmen, Pai Karlito e Pai Claudio (Ilê Olá Omi Ase Opo Araka), Pai Ronaldo, Maria Aparecida e João Rodolfo (Santuário Nacional da Umbanda).

22. Atualmente liderado por Mãe Paula.

23. Para mais informações: https://fcptsite.wixsite.com/ fcpt/single-post/2018/02/05/ Grupo-de-Trabal ho- "Territórios-Tradicionais-de-Matriz-Africana-Tombados"-de-São-Paulo-é-criado, por Pedro Neto.
O estudo da maioria destes bens teve como ponto de partida os laudos antropológicos, anexados aos processos de tombamento, feitos pelo Prof. Dr. Vagner Gonçalves da Silva ${ }^{20}$, do Departamento de Antropologia da USP, sendo feito de forma conjunta pela área técnica da UPPH, através da Historiadora Elisabete Mitiko Watanabe, juntamente com as lideranças dos terreiros citados ${ }^{21}$, e do Cientista Social José Pedro da Silva Neto, proponente do tombamento do Terreiro Santa Bárbara, que contribuiu de forma muito importante no desenvolvimento deste estudo. Também contou com a participação do Terreiro Axé llê Obá, tombado em $1990^{22}$.

Para tanto, foi criado o Grupo de Trabalho Territórios Tradicionais de Matriz Africana Tombados, que realizou um total de 8 reuniões, sendo a primeira na sede do IPHAN, as demais em cada um dos terreiros cujo tombamento foi solicitado, e a última no CONDEPHAAT ${ }^{23}$. No âmbito deste GT, se deu ampla discussão sobre a proteção de bens desta natureza, a partir de conceitos do patrimônio e das práticas cotidianas destes espaços culturais.

Os referidos laudos antropológicos e as discussões no Grupo de Trabalho foram fundamentais para elaboração do parecer técnico denominado "O Candomblé em São Paulo - Estudo de Patrimonialização de Terreiros", constante dos Processos 81.174/18 a 81.179/18, que apresentou, além informações sobre a trajetória desta religião em São Paulo, reflexões a respeito do uso do tombamento ou do registro como instrumentos adequados ao reconhecimento destes bens e sobre suas consequências para a dinâmica das terreiros.

A discussão sobre o uso do tombamento não é recente, já fazia parte dos estudos de terreiros realizados pelo IPHAN na década de 1980, que ensejou o tombamento do terreiro Casa Branca Engenho Velho, em Salvador - BA.

A questão central que se colocava, então e agora, é que o tombamento poderia vir a interferir na dinâmica de funcionamento do terreiro, uma vez que traz consigo a obrigatoriedade de que todas as intervenções sejam previamente aprovadas pelo órgão que protegeu o terreiro, ressaltando as questões burocráticas que envolvem tais aprovações.

As solicitações de aprovação envolvem a elaboração de projetos arquitetônicos e memoriais descritivos das intervenções que, para os terreiros, se configuram apenas na compra de materiais e a realização da reforma, muitas vezes utilizando a mão de obra dos filhos da casa. Agrega-se a isso o fato de que o tombamento pode trazer possíveis restrições que não permitam a realização de intervenções, como, por exemplo, demolição total das edificações para construção de um novo. Este entendimento está pautado na legislação já assentada e que rege o 
tombamento, que visa evitar que o bem tombado seja descaracterizado ${ }^{24}$.

Outro argumento, que questiona a adequação do tombamento como instrumento de proteção destes imóveis, acentua que os bens culturais de matriz africana apresentam características físicas comuns, o que dificultaria a aplicação do instrumento do tombamento, que, historicamente, vem sendo aplicado a bens que apresentassem características arquitetônicas, utilizando critérios como originalidade, monumentalidade ou raridade.

Sobre isso, a Historiadora Marly Rodrigues, em seu parecer a respeito de comunidades quilombolas do Vale do Ribeira ${ }^{25}$ grifo nosso) ressalta:

Já sobre os terreiros, temos ${ }^{26}$ : domblé em São Paulo - Estudo de Patrimonialização de Terreiros" constante dos Processos 81.174/18 a 81.179/18.

27. Institui o registro de bens culturais de natureza imaterial pelo IPHAN.
Os denominados remanescentes de quilombo, são, em geral, fruto de um outro contexto histórico; espacialmente podem ser comparados a bairros e, deste ponto de vista, assemelhamse e não se destacam de outros núcleos rurais. O que lhes dá realce é, portanto, o que ali resta da resistência e da antiga cultura afro-brasileira, quer traduzida na constituição do espaço, quer nas formas técnicas de fazer cotidiano e de relação com o lúdico e o religioso.

árvores consagradas, poço sagrado, etc, e cada terreiro construirá esse espaço de acordo com o tamanho do terreno, os recursos disponíveis, as necessidades do grupo. Trata-se, portanto, de uma arquitetura definida a partir de seu uso, sem uma preocupação estética efetiva.

Levando em consideração estas características, que não destacam nem a monumentalidade nem traços estéticos e originais do bem, pesaria o argumento a favor da adequação do uso registro dos terreiros como patrimônio imaterial, o fato de que $o$ ato não implica em restrições administrativas ao direito de propriedade e não estabelece a proteção física dos bens e, consequentemente, não há a obrigatoriedade de aprovação das intervenções nos imóveis, de modo que toda ação do órgão deve ser no sentido de salvaguardar a prática ali existente.

E a partir deste ponto de vista, a conclusão que pareceria óbvia é de que o melhor instrumento para o reconhecimento do valor cultural destes lugares seria o registro como patrimônio imaterial. A afirmação não é tão simples, tanto que o IPHAN, mesmo após a edição do Decreto $3551 / 00^{27}$, continuou a utilizar o tombamento como forma de proteção de terreiros. Vejamos.

Em 2011 houve a edição do Decreto 57.439, de

A conformação física de um terreiro não segue um padrão arquitetônico, embora haja espaços com denominações comuns como: barracão, quarto dos assentamentos dos orixás, cozinha, quarto para iniciações, assentamentos externos,
17/11//2011, que estabeleceu a competência do CONDEPHAAT para reconhecer os bens culturais de valor imaterial, e foi elaborado à luz da norma federal. Este decreto define o que pode ser 
registrado, incluindo lugares, conforme o artigo $1^{\circ}$, incluindo o conceito de lugar, que poderia ser aplicado para espaços físicos:

De acordo com o IPHAN ${ }^{28}$, o Livro de Registro de Lugares foram criados para registrar:

28. http://portal.iphan.gov.br/ pagina/detalhes/122.

29. De acordo com o site do IPHAN, foram registrados Cachoeira de lauaretê - Lugar Sagrado dos Povos Indígenas dos Rios Uaupés e Papuri (Amazonas); Feira de Campina Grande; Feira de Caruaru e Tava, Lugar de Referência para o Povo Guarani (Missões/RS).
Os bens de natureza imaterial que compõem o patrimônio cultural do Estado de São Paulo serão reconhecidos pelo Registro de Bens Culturais nos termos da legislação federal e estadual pertinentes, bem como na forma prevista neste decreto.

$\S 1^{\circ}$ - Constituem o patrimônio cultural imaterial do Estado de São Paulo, as formas de expressão e os modos de criar, fazer e viver, os conhecimentos e técnicas fundados na tradição, na transmissão entre gerações ou grupos, manifestadas individual ou coletivamente, portadores de referência à identidade, à ação, à memória como expressão de identidade cultural e social, tais como:

(...) 4. espaços onde se concentrem e se reproduzem práticas culturais coletivas.

simbólicas e narrativas, participando da construção dos sentidos de pertencimento, memória e identidade dos grupos sociais.

Aplicado ao caso dos terreiros, o registro do lugar pressupõe dizer que o valor cultural é a prática do Candomblé daquele grupo, naquele local, admitindo-se, portanto, que tal prática pode ser realizada em edificação de qualquer formato, desde que realizados os devidos rituais de assentamento que fundamentam a prática do Candomblé. Ou que a prática pode ser feita em um imóvel completamente diferente do atualmente existente, no mesmo endereço.

Analisando os lugares registrados pelo IPHAN ${ }^{29}$, o que se percebe é que tais registros se referem a lugares de uso coletivo mais amplo do que o espaço de um terreiro de Candomblé. Além disso, a listagem demonstra que não existem lugares da mesma prática registrados mais de uma vez, o que não ocorre com o tombamento.

(...) mercados, feiras, santuários, praças onde são concentradas ou reproduzidas práticas culturais coletivas. Lugares são aqueles que possuem sentido cultural diferenciado para a população local, onde são realizadas práticas e atividades de naturezas variadas, tanto cotidianas quanto excepcionais, tanto vernáculas quanto oficiais. Podem ser conceituados como lugares focais da vida social de uma localidade, cujos atributos são reconhecidos e tematizados em representações
Das discussões no Grupo de Trabalho e das leituras sobre o assunto, foi entendido que o espaço do terreiro, com todos os seus compartimentos se relaciona de forma muito íntima com os rituais, ou seja, não há candomblé sem terreiro, ele necessita de um espaço específico para ser praticado, devidamente preparado e consagrado, assim, não é possível separar a prática do lugar. Conforme nos explica SILVA (1995, p. 174): 
os terreiros, embora não precisando de templos especiais para suas instalações, caracterizamse por incorporarem em sua lógica de divisão do espaço físico inúmeras concepções cosmológicas relativas ao sagrado e ao profano, ao mistério ou ao segredo, e principalmente, ao poder religioso. Isto por que no Candomblé, os espaços e os objetos são vistos como locus de axé, da força vital que pode ser conservada, manuseada e transmitida. Considera-se o terreiro como um ser vivo ao qual deve-se, de tempos em tempos, homenagear com rituais e sacrifícios apropriados (chamados de dar de comer ao ari-axé - ponto central do barracão localizado no chão - ou à cumeeira - ponto no teto localizado acima do ari-axé) As instalações, assim sacralizadas são tidas como extensões do axé do orixá patrono do terreiro.

Para além disso, muitos terreiros instalados em áreas urbanas são lugares de referência para memória da cultura de matriz africana, são territórios que se consolidaram na paisagem. Assim, independente do seu uso, são marcas históricas deixadas na ocupação das cidades, assim como diversos outros bens que tiveram seus usos alterados, mas que permanecem como referências culturais.

E de todo modo, os terreiros de candomblé são suportes de memória, por excelência, como destaca SANT'ANNA, (s/d; p. 9) ${ }^{30}$ :

Sant'Ano escrito por Márcia discussões sobre a legislação federal de patrimônio imaterial e ocupou o cargo de direção do Departamento do Patrimônio Imaterial do IPHAN.
Os terreiros de candomblé são e sempre foram lugares de preservação de memórias. O próprio sistema religioso o exige. Isso se verifica tanto na reverência obrigatória aos ancestrais quanto na prática religiosa de marcar o lugar 'habitado' por uma divindade ou ainda na preservação dos rituais e da língua de cada "nação". Além disso, a relação da comunidade de culto com o espaço do terreiro é de caráter profundamente sagrado. O culto só pode ocorrer aí, pois no seu centro simbólico está enterrado o axé da casa - o conjunto de objetos e material orgânico que representa e fixa a força divina sem a qual não se dá a comunicação com o mundo dos orixás, dos voduns ou dos inquices, nem nada pode existir. Daí a importância fundamental da preservação do espaço para a continuidade da manifestação religiosa.

E como último argumento em defesa do uso do tombamento, e não do registro, destaca-se fato que tombamento impede a demolição total das edificações, o que acaba sendo uma garantia de permanência do uso. Para os atuais dirigentes das Casas, além do reconhecimento do valor cultural, o tombamento é também garantia de permanência das práticas no local e da manutenção da memória de todo o esforço para construção do lugar.

Nas discussões do Grupo de Trabalho, a defesa do uso do tombamento foi unanimidade entre as lideranças dos terreiros, tendo sido eles mesmos os interessados no pedido de proteção de suas casas. Como se sabe, são raros os casos em que o próprio proprietário solicita o tombamento de seu imóvel, pelo receio das restrições e perda de valor econômico. 


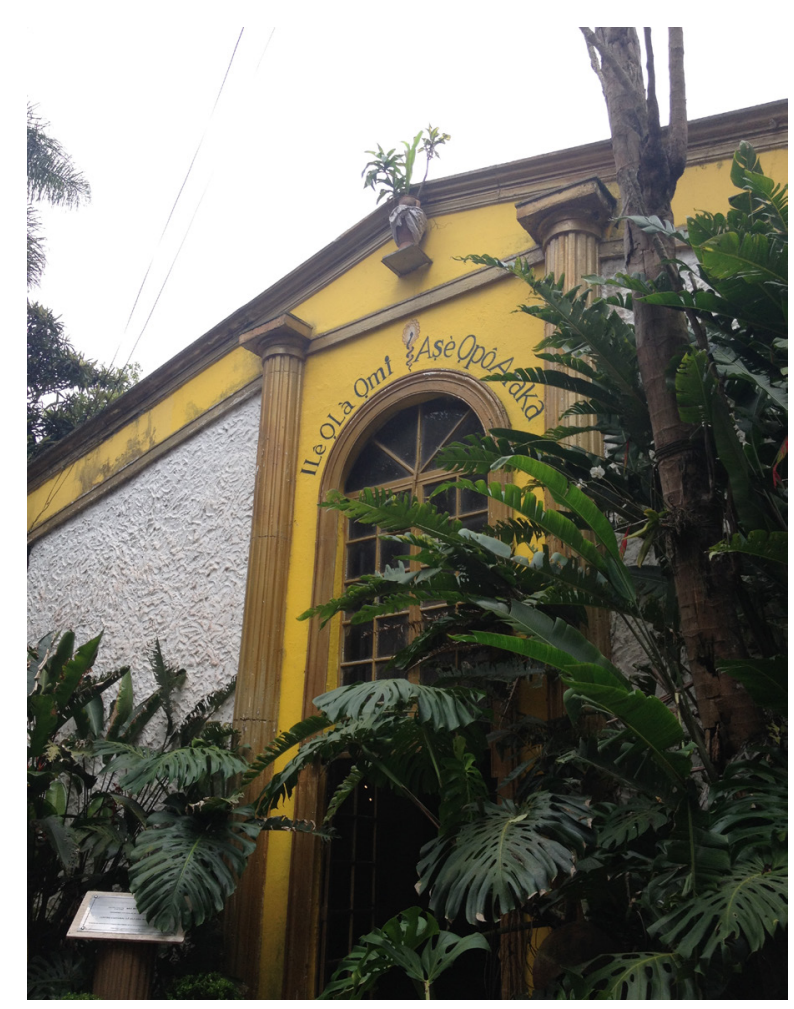

Figura 1. Fachada do llê Olá Omi Ase Opo Araka - São Bernardo do Campo. Foto: Adda Alessandra Piva Ungaretti.
Há entendimento de que com a proteção do Estado, o uso do imóvel para a prática do Candomblé está garantido. Embora esta lógica não esteja correta, e isso foi sinalizada nas diversas reuniões realizadas, o tombamento é visto como uma forma de proteção importante já que restringe a exploração econômica do imóvel, limitando outros usos, considerando a própria conformação dos edifícios, além de se configurar em ato que já conta com legislação consolidada, diferente do registro, cujo uso ainda apresenta dificuldades

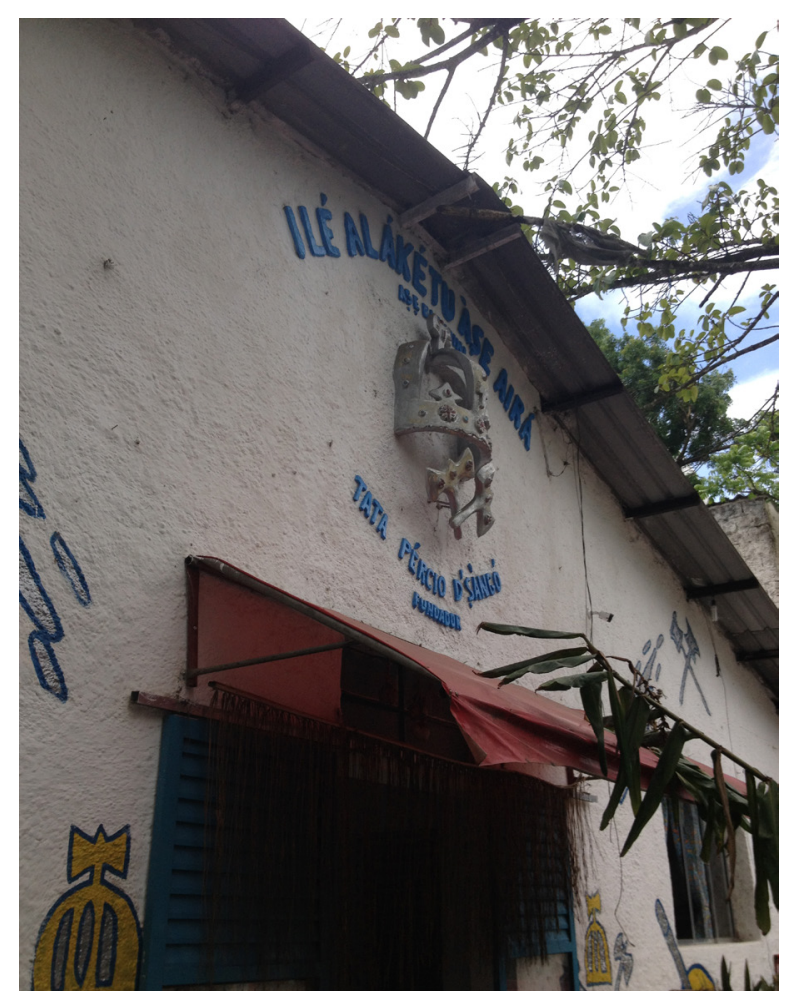

Figura 2. Fachada do Ilê Alaketu Ase Ayra - São Bernardo do Campo. Foto: Adda Alessandra Piva Ungaretti. de aplicação em São Paulo, pela ausência de regulamentos mais precisos.

De qualquer modo, os atuais dirigentes dos terreiros têm plena ciência da importância do processo de sucessão para manutenção das práticas no local. Como se enfatizou nas discussões do Grupo de trabalho: "o CONDEPHAAT tomba a cumeeira, mas não dá de comer".

Seguem figuras ilustrativas dos terreiros estudados:

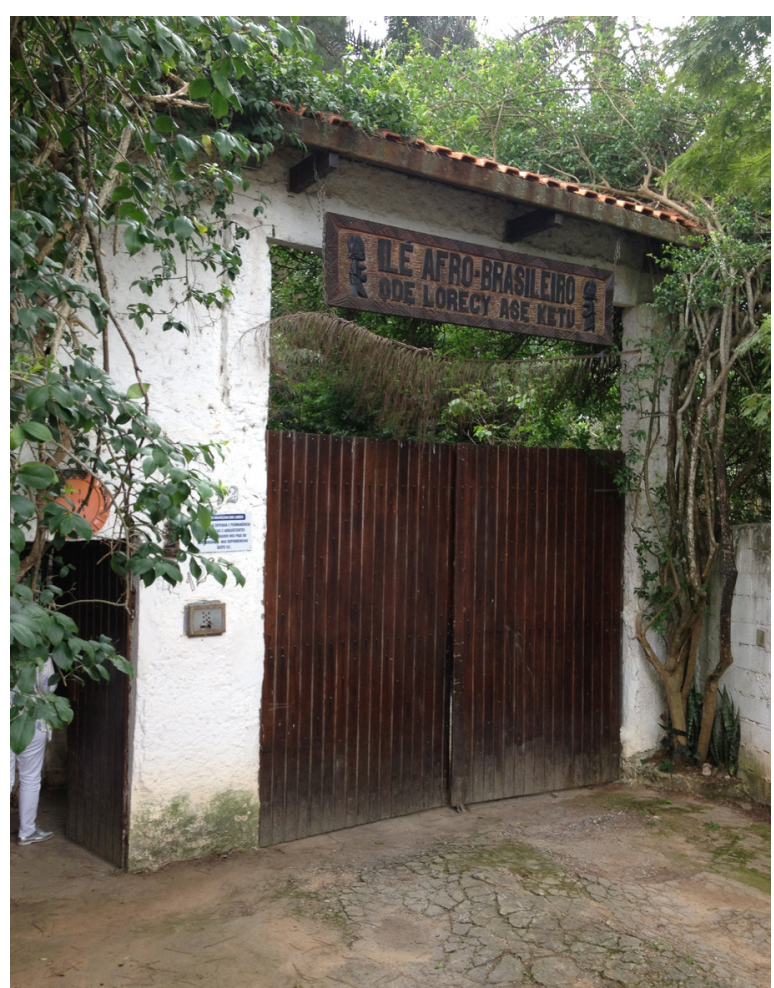

Figura 3. Fachada do llê Odê Lorecy - Embu das Artes. Foto: Adda Alessandra Piva Ungaretti. 


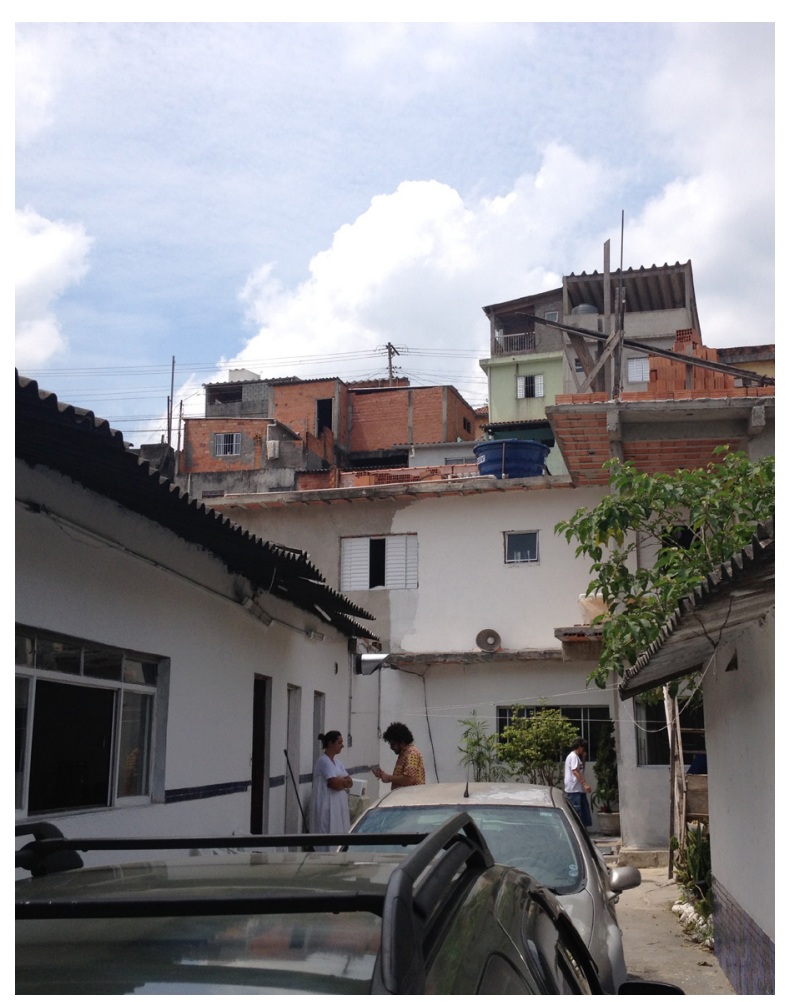

Figura 4. Terreiro Santa Bárbara - São Paulo. Foto: Adda Alessandra Piva Ungaretti.

Entendimento diferente foi dado ao Santuário Nacional da Umbanda, uma vez que esta religião tem uma relação diferente com o espaço. $O$ parecer técnico constante do processo 81.179/18 apresentou, do mesmo modo que nos processos relativos ao Candomblé, a trajetória da Umbanda em São Paulo e discussões relativas aos instrumentos de proteção. Os autos contaram também com laudo antropológico, elaborado pelo Prof. Dr. Vagner Gonçalves da Silva.

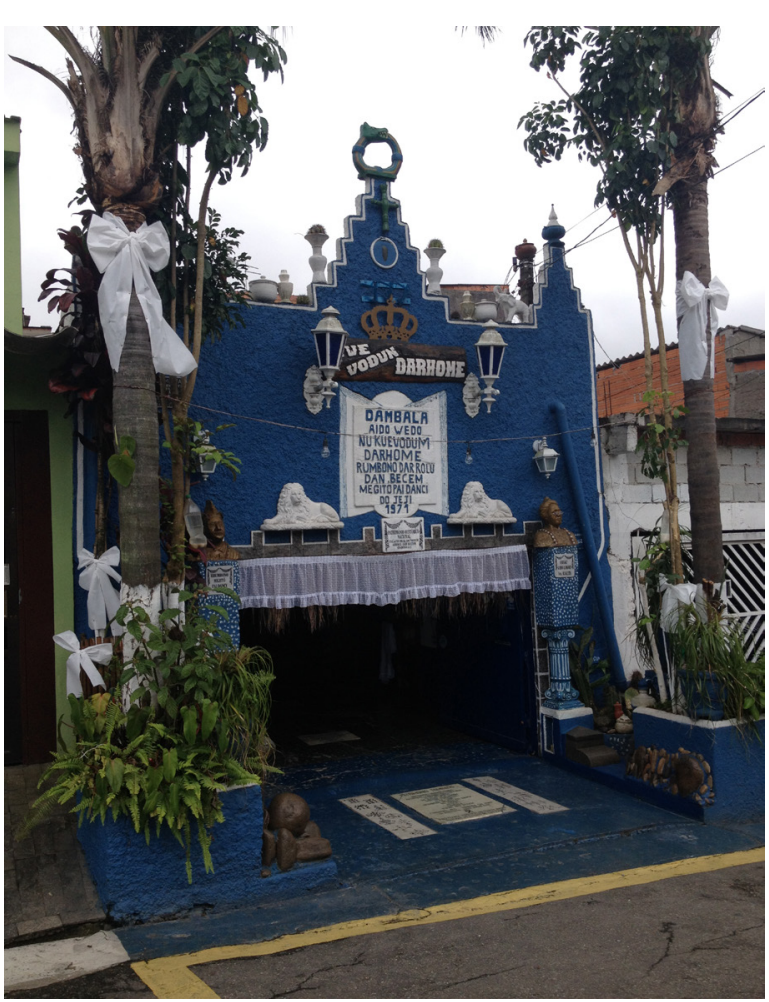

Figura 5. Fachada da Casa de Culto Dambala Kuere Rho Bessein - Santo André. Foto: Adda Alessandra Piva Ungaretti.

Da pesquisa realizada, verificou-se que o Santuário é um dos únicos espaços físicos ligados à memória da Umbanda, mantido até os dias atuais, sendo referência cultural para esta prática, que surge no Rio de Janeiro por volta de 1920, chegando em São Paulo no final desta década, com períodos de grande destaque, deixando também suas marcas na memória paulista e mesmo nas práticas cotidianas da sociedade, como simpatias, uso de elementos de proteção, pular sete ondas, etc. 


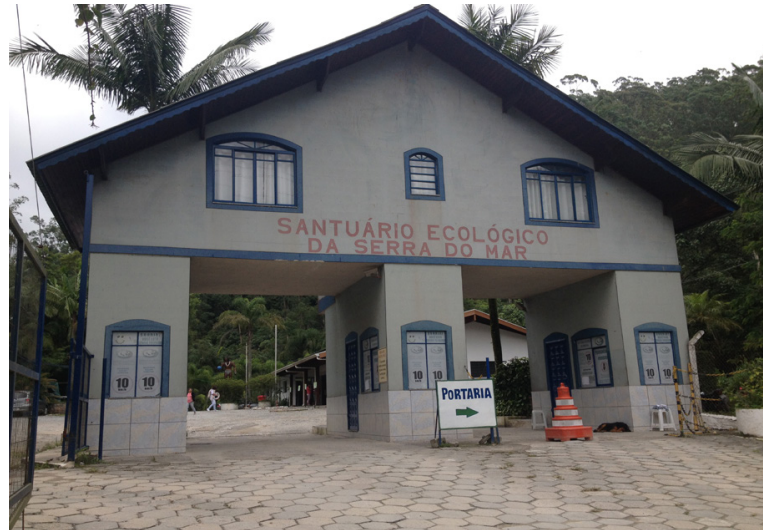

Figura 6. Entrada do Santuário. Foto: Adda Alessandra Piva Ungaretti.

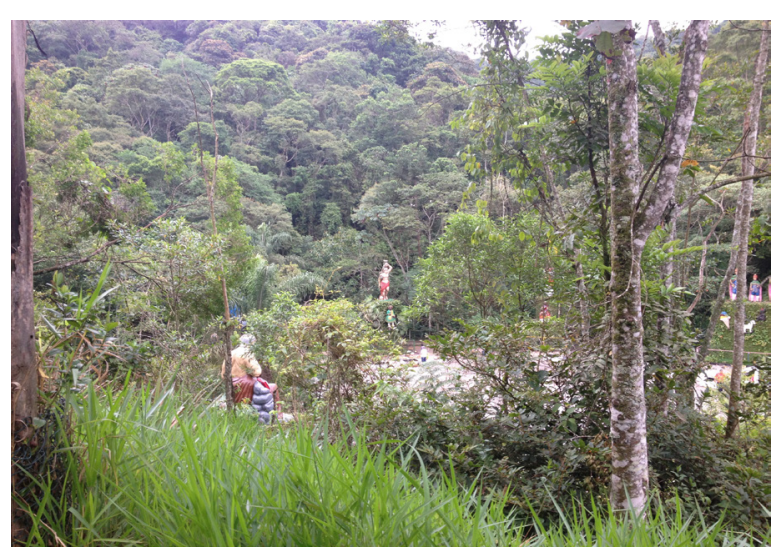

Figura 7. Vale dos Orixás. Foto: Adda Alessandra Piva Ungaretti.

31. Ata da reunião $n^{\circ} 1948$ do CONDEPHAAT.
Inaugurado na década de 1960, o local é administrado pela Federação Umbandista do Grande $A B C$ e situa-se em área de proteção ambiental, cujo uso foi concedido pela Prefeitura Municipal de Santo André. O local é formado por diversos espaços de terreiros, imagens de santos (associados aos Orixás) além de pontos naturais como cachoeira, lagos, matas, trilhas, onde são realizadas as práticas de adeptos da Umbanda e do Candomblé.

Do mesmo modo que o Candomblé, mais importante do que monumentos e edificações existentes, são as práticas coletivas que dão efetivo sentido ao local. Contudo, neste caso a proposta de proteção foi o de registro como patrimônio imaterial, na categoria lugar.

A Umbanda não tem, necessariamente, uma ligação sagrada com o espaço onde acontece a gira (cerimônia) podendo este ser trocado, readequado, sem que isso represente interferência nos rituais. Há terreiros de Umbanda que surgiram na década de 1960, que remanescem até os dias atuais, contudo, a pesquisa não localizou informações de estes se configurem como lugares de referências para a história da Umbanda. $\mathrm{O}$ próprio terreiro do Pai Ronaldo de Linares considerado figura histórica da Umbanda, apesar de sua antiguidade, não é um local histórico para a memória desta prática cultural em São Paulo. Outros nomes como Pai Jaú, Pai Jamil tampouco tem seus endereços de terreiro conhecidos.
Diferentemente do Candomblé, a Umbanda tem como referências marcantes as festas e manifestações públicas, como a Festa de lemanjá, na Praia Grande e outras cidades do litoral paulista, ou personalidades ligadas à história da consolidação da religião em São Paulo, os chamados decanos da Umbanda.

Assim, mais do que proteger um perímetro e seus elementos, houve necessidade de proteção também da manifestação coletiva que ocorre no local, de modo a valorizar e salvaguardar sua existência, incluindo o trabalho realizado pelos detentores que vem, desde o final da década de 1960, buscando formas de garantir a prática da Umbanda em lugar adequado e contribuindo para sua manutenção, com ações de preservação da área natural desta antiga pedreira, em conjunto com a Prefeitura de Santo André, que deverá se configurar num futuro plano de salvaguarda.

A partir deste entendimento, foi proposto o registro do Santuário como patrimônio imaterial, na categoria lugar.

Estas propostas técnicas de proteção foram encaminhadas ao CONDEPHAAT e aprovadas por unanimidade ${ }^{31}$, contudo, ainda aguardam avaliação do Secretário da Cultura e Economia Criativa para terem o reconhecimento consolidado, por meio da publicação da respectiva resolução de tombamento e registro. 


\section{Conclusão}

A questão central apresentada neste artigo - os instrumentos de preservação aplicado aos terreiros - não se encerra na conclusão dos estudos realizados para reconhecimento oficial destes bens. Tanto o tombamento de terreiros, como o registro do Santuário foram considerados os mais adequados pelos motivos expostos ao longo do presente artigo. Contudo ainda permanecem questões sobre como, de fato, valorizar a memória e história dos grupos sociais de matriz africana, para além do ato formal do tombamento e registro. Como coloca SANTANA (s/d; p. 10):

A dívida dos organismos de preservação para com a herança cultural material e imaterial legada pelos afrodescendentes no Novo Mundo ainda é grande. O reconhecimento da importância desse patrimônio, constituído também por outras manifestações religiosas, artísticas, literárias ou musicais, está apenas começando.

Paradoxalmente, os órgãos de preservação têm trabalhado no sentido de que seu trabalho se finaliza com o reconhecimento e que a valorização se resume a analisar projetos de intervenção em bens tombados. Neste sentido, as questões essenciais que envolvem a prática do registro do patrimônio imaterial, principalmente no que se refere à salvaguarda e participação social, talvez tragam certo arejamento sobre outras novas formas de pensar e agir sobre o patrimônio cultural.

\section{Referências}

AMARAL, Rita "O tombamento de um terreiro de candomblé em São Paulo". In: Comunicações do Iser: Rio de Janeiro, v. 41, 1991.

BENJAMIN, Walter. Sobre o conceito de História. In Magia e Técnica, Arte e Política - Ensaios sobre literatura e história da cultura. São Paulo: Brasiliense, 2012.

CONDEPHAAT. Bens protegidos. Disponível em http://CONDEPHAAT.sp.gov.br/bens-protegidos-online/. Acesso em 18/08/2019.

FONSECA, Maria Cecília Londres. Da modernização à participação: a política federal de preservação nos anos 70 e 80. In: Revista do Patrimônio n. 24, Cidadania. Brasília: IPHAN, 1996.

FENELON, Déa Ribeiro. Cultura e História Social: Historiografia e Pesquisa. In: Projeto História 10. Revista do Programa de Estudos de Pós-Graduados em História e do Departamento de História da PUC-SP. São Paulo: EDUC, 1993, p. 73-90.

RODRIGUES, Marly. Por que vocês querem conservar o patrimônio? In: Revista de História $\mathrm{n}^{\circ}$ 15, Faculdade de Ciências Sociais da UNESP. Assis, 1996, p. 175 a 196. 
RODRIGUES, Marly. Imagens do Passado - A SILVA, Vagner Gonçalves. Orixás da Metrópole. instituição do patrimônio em São Paulo 1969- Petrópolis: Vozes, 1995

1987. São Paulo, IMESP, 2000.

SANT'ANNA, Márcia. Escravidão no Brasil: os

SILVA, Vagner Gonçalves. Candomblé e Umterreiros de candomblé e a resistência cul- Paulo: Selo Negro, 2005. banda - Caminhos da Devoção Brasileira. São tural dos povos negros. s/ d. Disponível em: http://www.pontaojongo.uff.br/sites/default/files/ upload/escravidao_no_brasil_os_terreiros_de_ candomble_e_a_resistencia_cultural_dos_povos_negros.pdf. Acesso em 05/08/2019. 